\title{
Neujahrsvorsätze - wo sind sie geblieben?
}

\section{Bruno Kesseli}

Dr. med. et lic. phil., Chefredaktor

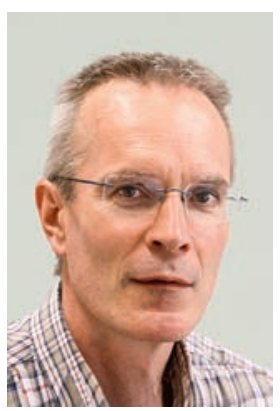

Sind Sie vor rund einem Monat mit guten Vorsätzen ins neue Jahr gestartet? Dann wäre der Zeitpunkt vielleicht nicht schlecht, eine kleine Zwischenbilanz zu ziehen. Sollte diese ernüchternd ausfallen, befinden Sie sich wahrscheinlich in guter Gesellschaft. Diese Erkenntnis habe ich nicht aus einer Studie, sie ist schlicht alltags-evidence-based.

Was mich selbst betrifft, kann ich mich nicht daran erinnern, je einen Neujahrsvorsatz gefasst zu haben. Woran das liegt, vermag ich nicht zu sagen. Eine plausible Hypothese könnte lauten, dass ich eventuelle Vorsätze im Festtrubel, vielleicht auch ein klein wenig äthylassoziiert, gleich wieder vergessen habe. Wie dem auch sei: Natürlich gehe auch ich nicht vorsatzfrei durchs Leben. Und vermutlich sieht meine Erfolgsbilanz nicht besser aus als diejenige der Menschen, die ihre Vorsätze an den Jahreswechsel knüpfen. Die meinen basieren aber in der Regel auf einer interessanten Lektüre oder einem inspirierenden Gespräch. Ich möchte sie dann sofort umsetzen und nicht bis zum nächsten Jahr damit warten. Dies scheint

\section{Auch als Arzt ist man immer wieder} mit gesundheitsrelevanten Vorsätzen seiner Patienten konfrontiert.

\section{Literatur \\ 1 New Year's resolutions: How do you make one you will keep? www.bbc.com/news/ uk-42353226 \\ 2 Ludvigsson JF. Håller vårdpersonal sina nyårslöften? [Do health professionals keep their new year's resolu- tions?]. Läkartidnin- gen. 2015, Dec 15;112. http://lakartidningen se/Aktuellt/Kultur/ Kultur/2015/12/ Haller-vardpersonal- sina-nyarsloften/}

bkesseli[at]emh.ch mir auch deshalb nicht sinnvoll, weil viele Vorsätze zum Ziel haben, die eigene Gesundheit und damit die Freude am Leben zu verbessern.

Auch als Arzt ist man immer wieder mit gesundheitsrelevanten Vorsätzen seiner Patienten konfrontiert. Vor diesem Hintergrund wäre es interessant zu wissen, ob es evidenzbasierte Hinweise darauf gibt, wie sich die Chancen auf ein nachhaltiges Umsetzen von Vorsätzen optimieren lassen. Diese Strategien könnte man dann den Patienten vermitteln.

In diesem Zusammenhang stiess ich kürzlich auf einen interessanten Beitrag der BBC-Serie «Reality Check» [1]. Der Artikel fasst Erkenntnisse verschiedener Forscher aus Sozial-, Geistes- und Neurowissenschaften zusammen, die zumindest für mich teilweise überraschend waren. Den Vorsatz auf das Wiedererlangen von etwas
«Verlorenem» zu richten, scheint demnach erfolgversprechender als etwas Neues gewinnen zu wollen. «Das Verlorene» kann zum Beispiel ein vernachlässigtes Hobby sein oder der frühere Fitness-Level. Der zugrundeliegende Mechanismus, so wird postuliert, sei eine dem Menschen inhärente "Verlustaversion». Weniger überraschend ist, dass Vorsätze realistisch sein sollten. Ausserdem hilft es, sie detailliert auszuarbeiten. "Jeden Freitag Fisch essen» ist besser als einfach "mehr Fisch essen». Ausnahmen sollten von Vorneherein

Der Artikel mit dem Titel «Do health professionals keep their new year's resolutions?» müsste eigentlich die Antworten bereithalten.

definiert sein, damit Ad-hoc-Ausreden nicht einfach fallen. Zum Beispiel darf der Spaziergang am eigenen Geburtstag ausfallen, nicht aber, wenn es regnet. Besonders erfolgreich sind offenbar Vorsätze, mit denen man auch jemand Nahestehendem etwas zugutetut oder bei denen andere Personen einfach nur involviert sind. Auch wenn der eigene Ruf bei Nichteinhalten des Vorsatzes leidet, ist dies der Motivation förderlich. Vorsätze bis zu einem gewissen Grad öffentlich zu machen, kann deshalb eine gute Idee sein. Fazit: Wer sich nur auf seine Willenskraft verlässt, hat schlechte Karten. Planung ist (fast) alles.

«PubMed» listet unter dem Stichwort «New Year's resolutions» übrigens immerhin 70 Artikel auf. Gern hätte ich Ihnen verraten, wie die Erfolgsbilanz bei Ärztinnen und Ärzten aussieht. Der im Volltext frei zugängliche Artikel mit dem Titel «Do health professionals keep their new year's resolutions?» müsste eigentlich die Antworten bereithalten. Doch nach der Lektüre des ersten Satzes musste ich die Übung leider abbrechen. Ich hoffe, Sie werden es mir nachsehen. Er lautet nämlich wie folgt: Livsstilssjukdomar står för en hög andel av sjuklighet i västvärlden, och när WHO rankade de tio ledande dödsorsakerna i världen 2014 hade alla listade dödsorsaker - åtminstone delvis - livsstilsrelaterade riskfaktorer [2]. 